\title{
Climate sensitivity estimates - sensitivity to radiative forcing time series and observational data
}

\author{
Ragnhild Bieltvedt Skeie ${ }^{1}$, Terje Berntsen ${ }^{1,2}$, Magne Aldrin ${ }^{3}$, Marit Holden ${ }^{3}$, and Gunnar Myhre ${ }^{1}$ \\ ${ }^{1}$ CICERO-Center for International Climate and Environmental Research - Oslo, \\ P.O. Box 1129 Blindern, 0318 Oslo, Norway \\ ${ }^{2}$ Department of Geosciences, University of Oslo, P.O. Box 1047 Blindern, 0316 Oslo, Norway \\ ${ }^{3}$ Norwegian Computing Center, P.O. Box 114 Blindern, 0314 Oslo, Norway \\ Correspondence: Ragnhild Bieltvedt Skeie (r.b.skeie@cicero.oslo.no)
}

Received: 1 December 2017 - Discussion started: 19 December 2017

Revised: 30 April 2018 - Accepted: 1 June 2018 - Published: 21 June 2018

\begin{abstract}
Inferred effective climate sensitivity $\left(\mathrm{ECS}_{\text {inf }}\right)$ is estimated using a method combining radiative forcing (RF) time series and several series of observed ocean heat content (OHC) and near-surface temperature change in a Bayesian framework using a simple energy balance model and a stochastic model. The model is updated compared to our previous analysis by using recent forcing estimates from IPCC, including OHC data for the deep ocean, and extending the time series to 2014. In our main analysis, the mean value of the estimated $\mathrm{ECS}_{\text {inf }}$ is $2.0^{\circ} \mathrm{C}$, with a median value of $1.9^{\circ} \mathrm{C}$ and a $90 \%$ credible interval $(\mathrm{CI})$ of $1.2-3.1^{\circ} \mathrm{C}$. The mean estimate has recently been shown to be consistent with the higher values for the equilibrium climate sensitivity estimated by climate models. The transient climate response (TCR) is estimated to have a mean value of $1.4{ }^{\circ} \mathrm{C}$ $\left(90 \% \mathrm{CI} 0.9-2.0^{\circ} \mathrm{C}\right)$, and in our main analysis the posterior aerosol effective radiative forcing is similar to the range provided by the IPCC. We show a strong sensitivity of the estimated ECS $_{\text {inf }}$ to the choice of a priori RF time series, excluding pre-1950 data and the treatment of OHC data. Sensitivity analysis performed by merging the upper $(0-700 \mathrm{~m})$ and the deep-ocean OHC or using only one OHC dataset (instead of four in the main analysis) both give an enhancement of the mean $\mathrm{ECS}_{\text {inf }}$ by about $50 \%$ from our best estimate.
\end{abstract}

\section{Introduction}

A key question in climate science is how the global mean surface temperature (GMST) responds to changes in greenhouse gases or other forcings. Climate sensitivity is determined by complex feedbacks that operate on very different timescales and may depend on the transient climate state. The standard metric for climate sensitivity is the equilibrium climate sensitivity (ECS) (or Charney sensitivity) given as the change in temperature at equilibrium for a doubling of $\mathrm{CO}_{2}$, neglecting long-term feedbacks associated with vegetation changes, carbon feedbacks and ice sheet dynamics. Estimates of the ECS are either based on complex climate models or observations of past climate (Collins et al., 2013; Knutti et al., 2017). The Intergovernmental Panel on Climate Change (IPCC) presented a likely ( $>66 \%$ probability) range for ECS of 1.5 to $4.5^{\circ} \mathrm{C}$ (Collins et al., 2013).
Regarding the Earth as a climate laboratory and the changes in atmospheric composition and land use over the historical record as a perturbation experiment, observationally based analyses of Earth's energy budget have been used to infer the climate sensitivity (Forster, 2016). Since the current climate is in a nonequilibrium state, observationally based methods can only account for the feedbacks operating during the historical period. These methods using the historical period with observations are referred to as inferred estimates (Armour, 2017; Forster, 2016) and only have the capability to derive an effective climate sensitivity and are generally significantly lower than ECS estimates from atmosphere-ocean general circulation models (AOGCMs) (Armour, 2017; Knutti et al., 2017).

Since the IPCC's fifth assessment report (AR5), there has been an improved understanding of the causes of the 
differences in estimates of climate sensitivity from climate models and observationally based methods for two main reasons. First, recent analysis of time-varying feedbacks in AOGCM simulations from Coupled Model Intercomparison Project Phase 5 (CMIP5) (Proistosescu and Huybers, 2017; Armour, 2017; Andrews et al., 2015) has indicated that in most AOGCMs the net feedbacks become more positive over time as a new equilibrium is approached. This is most likely due to the evolution of the pattern of sea surface temperature increase in the Pacific and Southern oceans and associated cloud feedbacks. Whether this slow warming has manifested itself in the climate record used for the analysis is the difference between effective and equilibrium climate sensitivity (Armour, 2017; Knutti et al., 2017). Second, ECS formally refers to global near-surface air temperature ("tas" in CMIP5 nomenclature), and in observationally based methods observed surface temperature records that are a blend of air temperature over land and sea surface temperature (SST) over ocean are used in the estimation. Several observed surface temperature records exist with different methods to account for gaps in the observations. Differences in historical surface temperature warming among various analyses is more than $0.1{ }^{\circ} \mathrm{C}$ (Haustein et al., 2017), arising mainly from approaches taken in regions that are missing or have limited spatial coverage of observations. According to Richardson et al. (2016), there is a general bias in the surface temperature records since water heats more slowly than the air above and due to undersampling in fast-warming regions (e.g., the Arctic). Taking both effects into account, Armour (2017) shows that previous estimates of inferred effective climate sensitivity (ECS $\mathrm{Enf}_{\text {inf }}$ ) of about $2.0^{\circ} \mathrm{C}$ are consistent with estimates of ECS of $2.9^{\circ} \mathrm{C}$ from climate models.

Although it is now established that the ECS estimated by the use of complex climate models and ECS inf $_{\text {estimated by }}$ using historical observations would differ, there is still considerable spread in ECS estimates from models and between

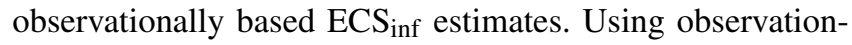
ally based methods and complex models are complementary approaches to quantifying the net effect of the feedbacks that determine the climate sensitivity. Complex climate models include processes that are highly parameterized, in particular the representation of clouds, precipitation and convection, and associated feedbacks, which are crucial for estimating the ECS (Bony et al., 2015; Tan et al., 2016). There is also a large spread in observationally based estimates (Knutti et al., 2017). A better understanding of the feedbacks in the complex models as well as improvements and understanding differences among the observationally based methods are needed.

Observational estimates of climate sensitivity can be improved using longer data series of higher quality (e.g., correcting for observational biases in temperatures or better forcing estimates) (Urban et al., 2014). Estimates can also be improved by including observational data on other climate variables which were not previously available. Several stud- ies indicate that the temporary slowdown in GMST at the beginning of the millennium coexisted with increased accumulation of heat in the deep ocean (e.g., Meehl et al., 2011, 2013; Balmaseda et al., 2013; Watanabe et al., 2013; Chen and Tung, 2014; Lyman and Johnson, 2013). Johansson et al. (2015) found that if ocean heat content (OHC) change below $700 \mathrm{~m}$ over this period were included in their observationally based methods, the mean value of ECS $_{\text {inf }}$ would increase.

In this study we use our estimation model that was first documented in Aldrin et al. (2012) and further developed in Skeie et al. (2014). Our method is more complex than the common energy-balance-based estimates (Forster, 2016) in that we embed a simple climate model into a stochastic model with radiative forcing time series as input, treating the Northern and Southern Hemisphere (NH and SH) separately and including a vertical resolution of the ocean (40 layers). The radiative forcing time series are linked to the observations of $\mathrm{OHC}$ and temperature change through the simple climate model and the stochastic model, using a Bayesian approach. A unique feature with our method is that we use several observational datasets. The method estimates not only the ECS $\mathrm{Sinf}_{\text {inf }}$ but simultaneously also provides posterior estimates of the radiative forcing, as well as posterior uncertainty estimates in the observations datasets and correlations between them. In this study we further develop our estimation model with additional observational datasets, including heating rates of the deep ocean (below $700 \mathrm{~m}$ ), new forcing time series from the IPCC AR5 as well as extended time series from 2010 to 2014 to update our estimate of ECS $_{\text {inf }}$. We carry out a number of sensitivity experiments to investigate causes of differences in observationally based ECS $_{\text {inf }}$ estimates due to differences in the input data (observations of surface temperature, $\mathrm{OHC}$ and radiative forcing (RF)).

\section{Data and methods}

\subsection{The model}

Our full model consists of a simple climate model (SCM) with an idealized representation of the Earth's energy balance, a data model that describes how observations are related to the process states and finally a parameter model that expresses our prior knowledge of the parameters (Aldrin et al., 2012).

The core of our model framework is the SCM, a deterministic energy balance/upwelling diffusion model (Schlesinger et al., 1992). The SCM calculates annual hemispheric nearsurface temperature change (blended SST and surface air temperature) and changes in global $\mathrm{OHC}$ as a function of estimated RF time series. The vertical resolution of the ocean is 40 layers down to $4000 \mathrm{~m}$. The output of the SCM can be written as $m_{t}\left(x_{1750: t}, \boldsymbol{\theta}\right)$, where $x_{1750: t}$ (the RF from 1750 until year $t$ ) and $\boldsymbol{\theta}$ are the true, but unknown, input values to the SCM. $\boldsymbol{\theta}$ is a vector of seven parameters, each with a physical 
Table 1. List of data used in the estimation, the abbreviation used in the text, references, in which cases the datasets are used, and time of download. The months in parentheses are when data used in case A (see Sect. 2.2) were downloaded.

\begin{tabular}{|c|c|c|c|}
\hline Abbreviation & References & $\begin{array}{l}\text { Dataset used } \\
\text { in case }\end{array}$ & Downloaded \\
\hline \multicolumn{4}{|c|}{ Surface temperature change } \\
\hline GISS & Hansen et al. $(2006,2010)$ & $\mathrm{A}, \mathrm{B}, \mathrm{C}, \mathrm{D}, \mathrm{E}$ & March 2015 (March 2011) \\
\hline HadCRUT4 & Morice et al. (2012) & $\mathrm{A}, \mathrm{B}, \mathrm{C}, \mathrm{D}, \mathrm{E}$ & March 2015 (March 2011*) \\
\hline NCDC & Smith and Reynolds (2005), Smith et al. (2008) & $\mathrm{A}, \mathrm{B}, \mathrm{C}, \mathrm{D}, \mathrm{E}$ & March 2015 (June 2011) \\
\hline CowtanWay & Cowtan and Way (2014) & $\mathrm{A}, \mathrm{B}, \mathrm{C}, \mathrm{D}, \mathrm{E}$ & March 2015 (April 2014) \\
\hline \multicolumn{4}{|c|}{ Ocean heat content upper $700 \mathrm{~m}$} \\
\hline Levitus & Levitus et al. (2009) & $\mathrm{A}, \mathrm{B}, \mathrm{C}, \mathrm{E}$ & March 2015 (March 2011) \\
\hline CSIRO & Domingues et al. (2008), Church et al. (2011) & $\mathrm{A}, \mathrm{B}, \mathrm{C}, \mathrm{E}$ & April 2014 (October 2011) \\
\hline Ishii and Kimoto & Ishii and Kimoto (2009) & $\mathrm{A}, \mathrm{B}, \mathrm{C}, \mathrm{E}$ & March 2015 (October 2011) \\
\hline ORAS4 & Balmaseda et al. (2013) & $\mathrm{B}, \mathrm{C}, \mathrm{E}$ & March 2015 \\
\hline \multicolumn{4}{|c|}{ Ocean heat content below $700 \mathrm{~m}$} \\
\hline ORAS4 & Balmaseda et al. (2013) & $\mathrm{B}, \mathrm{C}, \mathrm{E}$ & March 2015 \\
\hline \multicolumn{4}{|c|}{ Ocean heat content above $2000 \mathrm{~m}$} \\
\hline Levitus2000 & Levitus et al. (2012) & $\mathrm{D}$ & July 2015 \\
\hline \multicolumn{4}{|l|}{ SOI index } \\
\hline SOI & $\begin{array}{l}\text { Southern Oscillation index, Bureau of Meteorology, Australia } \\
\text { http://www.bom.gov.au/climate/current/soihtm1.shtml }\end{array}$ & $\mathrm{A}, \mathrm{B}, \mathrm{C}, \mathrm{D}, \mathrm{E}$ & March 2015 (November 2011) \\
\hline \multicolumn{4}{|l|}{ Forcing time series } \\
\hline Forc_Skeie14 & Skeie et al. $(2011,2014)$ & A & \\
\hline Forc_AR5 & Myhre et al. (2013) & $\mathrm{B}, \mathrm{C}, \mathrm{D}, \mathrm{E}$ & \\
\hline
\end{tabular}

* HadCRUT3.

meaning. One of these parameters is the climate sensitivity, and the other parameters determine how the heat is mixed into the ocean, which includes the mixed layer depth, the air-sea heat exchange coefficient, the vertical diffusivity in the ocean and the upwelling velocity (see Schlesinger et al., 1992 and Aldrin et al., 2012 for details).

The true state of some central characteristics $\left(g_{t}\right)$ of the climate system in year $t$ with corresponding observations can then be written as $g_{t}=m_{t}\left(x_{1750: t}, \boldsymbol{\theta}\right)+n_{t}$, where $n_{t}$ is a stochastic process, with three terms, representing long-term and short-term internal variability and model error. For the short-term internal variability, we use the Southern Oscillation index (Table 1) to account for the effect of El NiñoSouthern Oscillation (ENSO). The term for the long-term internal variability was implemented in Skeie et al. (2014), and the dependence structure of this term (i.e., correlations over time and between the three elements) is based on control simulations with a general circulation model from CMIP5 (see Skeie et al., 2014, for details) This term will also represent other slowly varying model errors due to potential limitations of the SCM and forcing time series. The third error term is included to account for more rapidly varying model errors.
For the (available) long-term observational data that defines $g_{t}$ we consider the surface temperatures separately for the Northern and Southern Hemispheres and the OHC separately for $0-700 \mathrm{~m}$ and below $700 \mathrm{~m}$. Each of these elements of $g_{t}$ are associated with one or more corresponding observationally based data series (Table 1), with individual error terms. To gain as much information as possible, we use several datasets for the same physical quantity (e.g., OHC above $700 \mathrm{~m}$ ) simultaneously (Aldrin et al., 2012; Skeie et al., 2014). Most of the data series are provided with corresponding yearly standard errors (Fig. S7a in the Supplement). However, we only use the temporal profiles of the reported errors and estimate their magnitudes within the model, taking into account the possibilities that the reported standard errors may under- or overestimate the true uncertainty (Appendix A and Aldrin et al., 2012; Skeie et al., 2014).

The unknown quantities are given prior distributions as

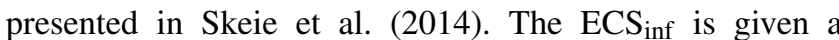
vague prior, uniform $(0,20)$, and the informative priors for $\boldsymbol{\theta}$ based on expert judgment are listed in Table S1. We apply a Bayesian approach in the spirit of Kennedy and O'Hagan (2001) to the calibration of computer models and 

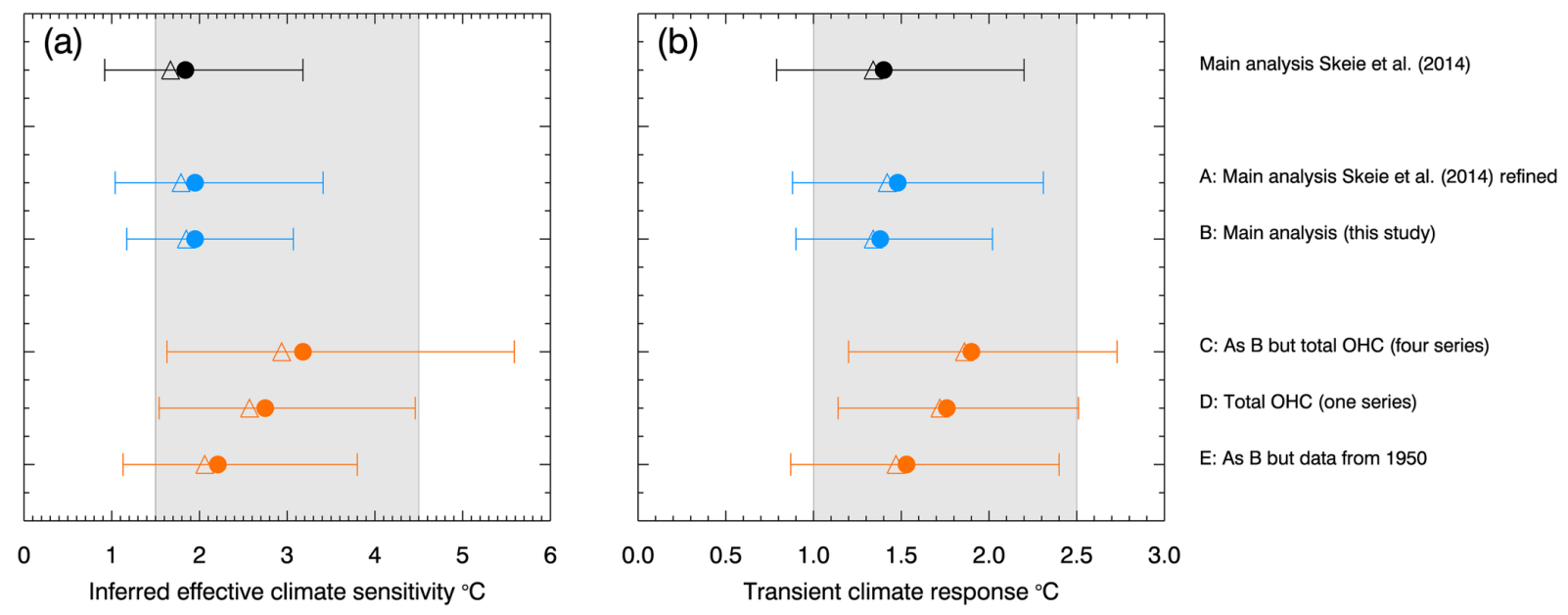

Figure 1. Posterior $90 \% \mathrm{CI}$ for $\mathrm{ECS}_{\text {inf }}$ (a) and TCR (b) for the different analyses in this study. The estimated posterior mean is indicated by a dot and the median by an open triangle. The IPCC AR5 likely range ( $>66 \%$ probability) for ECS (a) and TCR (b) is presented as gray shading. Figure S2 show the corresponding probability density functions.

use Markov Chain Monte Carlo (MCMC) techniques to sample from the posterior distribution (Aldrin et al., 2012).

\subsection{Setup}

The starting point, here called case $\mathrm{A}$, is the main result from Skeie et al. (2014) (hereafter named Skeie14) with some modifications (see Appendix A). These modifications changed the mean $\mathrm{ECS}_{\text {inf }}$ value from $1.8^{\circ} \mathrm{C}$ (median $1.7^{\circ} \mathrm{C}$, $90 \%$ credible interval $(\mathrm{CI}) 0.92-3.2^{\circ} \mathrm{C}$ ) to $2.0^{\circ} \mathrm{C}$ (median $1.8^{\circ} \mathrm{C}, 90 \% \mathrm{CI} 1.0-3.4^{\circ} \mathrm{C}$ ) (Fig. 1a, case A). The transient climate response (TCR) is calculated by running the model with $1 \%$ per year increase in $\mathrm{CO}_{2}$ using the joint posterior distribution of the model parameters. These modifications increased the mean value of TCR from 1.4 to $1.5^{\circ} \mathrm{C}$ and the $90 \%$ CI shifted slightly to larger values (Fig. 1b).

In case A, we used four hemispheric pairs of observationally based estimates of surface temperatures from about 1880 to 2010 and three series for OHC above $700 \mathrm{~m}$ from about 1950 to 2010 and RF from Skeie et al. (2011, 2014) (Table 1). The forcing time series used in case A are hereafter named Forc_Skeie2014 and the priors of each forcing mechanisms included (Table S2) are described in detail in the Appendix D of Skeie14.

The potential for improving the constraint of the estimate of the climate sensitivity using observationally based methods depends crucially on the quality of the input forcing data and the quality and amount of observational data. In case B, we include new and improved knowledge of the forcing time series and add new data for OHC below $700 \mathrm{~m}$, and observational data are extended to 2014. More specifically, in case B we did the following:
1. replaced the Forc_Skeie14 prior with the AR5 effective radiative forcing (ERF) estimates (Myhre et al., 2013), hereafter named Forc_AR5. The priors for the forcing mechanisms included (Table S2) are constructed to be consistent with the uncertainties provided in AR5 and the same relative uncertainty for the prior forcing is used over the entire time period. ERF includes rapid adjustments allowing the full influence on clouds except through surface temperature changes (Sherwood et al., 2014; Boucher et al., 2013; Myhre et al., 2013).

2. included data for OHC below $700 \mathrm{~m}$ (ORAS4) and added one extra data series for OHC above $700 \mathrm{~m}$ (also ORAS4). Note that the deep-ocean OHC is added as a separate dataset and not merged with the upper ocean. Including data on $\mathrm{OHC}$ in the deep ocean thus has the potential to better constrain the parameters in the SCM that determine how the heat is mixed into the ocean as well as the posterior estimates of the effective radiative forcing.

3. used updated versions of the data prior to 2010 .

4. extended the time series from 2010 to 2014 .

Previous studies using similar methods have obtained different results with respect to the estimated ECS $_{\text {inf }}$ (Knutti et al., 2017). We perform three sensitivity experiments to investigate the effects of different choices about how to use OHC data (cases C and D, Sect. 4.1) and how sensitive the results are to pre-1950 data (case E, Sect. 4.2). 

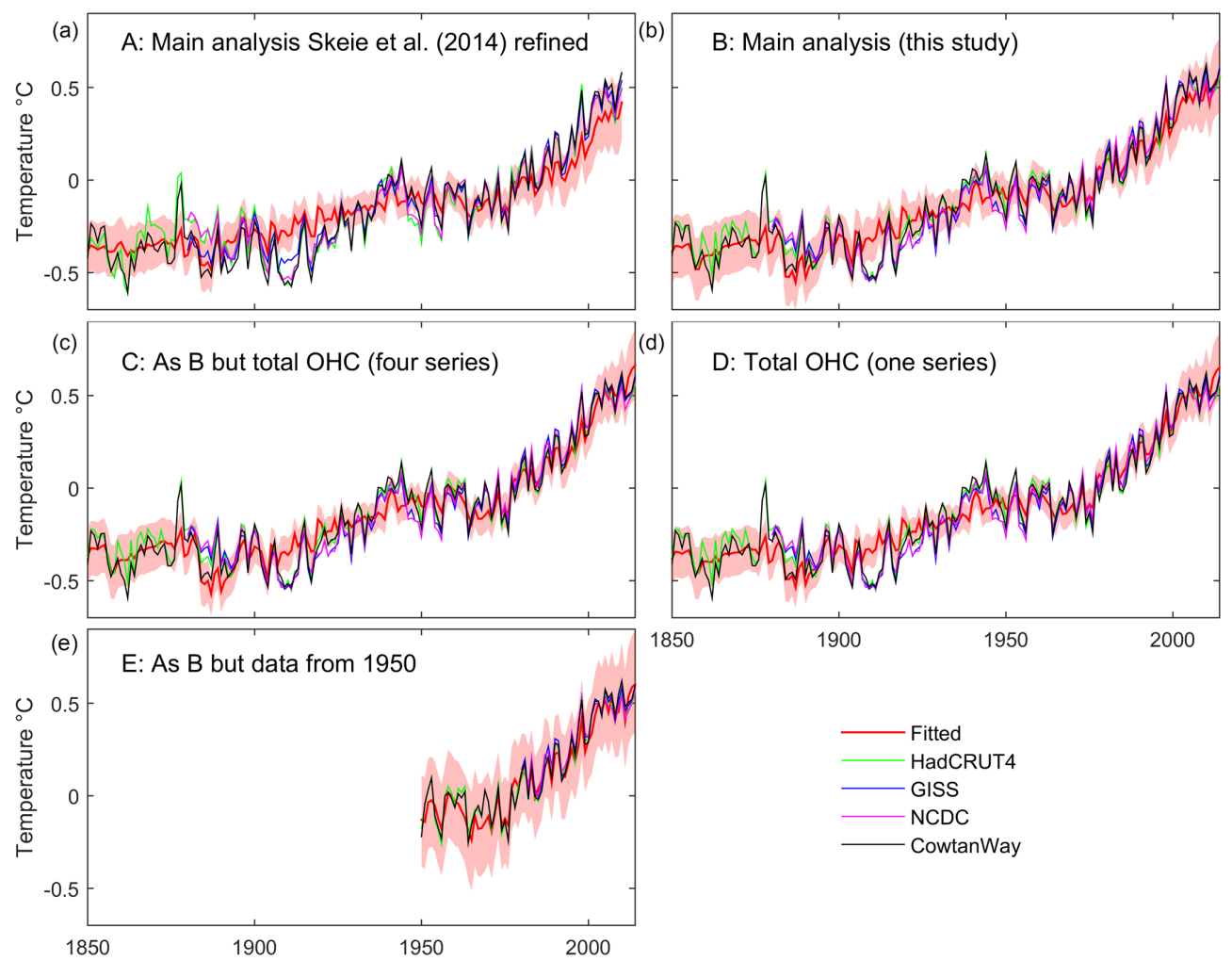

1900

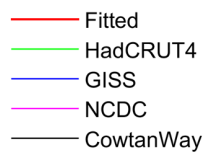

Figure 2. Observed and fitted (posterior mean) values for the GMST for cases A to E (a-e). The shaded areas show the $90 \%$ CI for fitted values, i.e., the sum of the output from the deterministic SCM and the short-term internal variability excluding the terms for long-term internal variability and model error. Figure S3 shows three sets of fitted values for the GMST for the main analysis that include the long-term internal variability and model error.

\section{Improved estimate of inferred effective climate sensitivity}

Here we present our revised estimate of ECS inf $_{\text {by replac- }}$ ing the RF prior with IPCC data, including OHC data below $700 \mathrm{~m}$ and extending the time series to 2014 (case B). We consider this analysis using the IPCC forcing estimates, including deep-ocean $\mathrm{OHC}$ and extending the length of the input data series as the most trustworthy and physically based case and thus regard it as our main estimate of the $\mathrm{ECS}_{\mathrm{inf}}$, with a mean of $2.0^{\circ} \mathrm{C}$ (median $1.9^{\circ} \mathrm{C}, 90 \%$ CI $1.2-3.1^{\circ} \mathrm{C}$ ). The mean value is similar while the $90 \% \mathrm{CI}$ is narrower compared to the refined Skeie14 estimate (Fig. 1a). The individual influence of the four major updates between cases A and $\mathrm{B}$ is shown in Fig. S1 and described at the end of this section. The mean value of TCR in case B is $1.4^{\circ} \mathrm{C}$ (median $1.3^{\circ} \mathrm{C}, 90 \% \mathrm{CI} 0.9-2.0^{\circ} \mathrm{C}$ ) (Fig. 1b). As for the $\mathrm{ECS}_{\text {inf }}$ estimate, the TCR mean value is similar and the $90 \% \mathrm{CI}$ is narrower compared to the refined Skeie14 estimate (Fig. 1b). The GMST change is well reproduced (Fig. 2, case B), and less of the recent GMST change is attributed to long-term internal variability compared to the refined Skeie14 estimate (Fig. S5a-b).
The rate of change in anthropogenic forcing is larger between 1940 and 1970 using Forc_AR5 compared to Forc_Skeie14 (Fig. 3). The fit to the GMST in the 1980s1990s improved (Fig. 2 case B vs. A), where the root mean square error between 1980 and 1999 decreased from 0.12 to $0.077^{\circ} \mathrm{C}$. Figure $\mathrm{S} 5$ shows posterior estimates of the longterm internal variability, the ENSO term and the model errors. Parts of the increase in GMST over the last decades are explained as long-term internal variability, but the amplitude decreases in case B compared to case A (Fig. S5a-b). In case $\mathrm{B}$, the estimated amplitude of the multi-decadal internal variability (about $0.2^{\circ} \mathrm{C}$ in each hemisphere, cf. Fig. S5) is in good agreement with the decadal trends in global surface temperatures found in unforced control simulations in the multi-model ensemble from CMIP5 $\left(0.2-0.4^{\circ} \mathrm{C}\right.$; Palmer and McNeall, 2014).

The prior anthropogenic mean forcing in 2010 increased from 1.5 to $2.3 \mathrm{~W} \mathrm{~m}^{-2}$ from case $\mathrm{A}$ to case $\mathrm{B}$ when Forc_AR5 replaced Forc_Skeie14. For case A, the posterior forcing is shifted to higher values compared to the prior, suggesting that the historical data and our method support higher forcing than the Forc_Skeie14 prior. When the prior is changed to Forc_AR5 in case B, the posterior for the anthropogenic forcing is much closer to the prior (Fig. 3), which in- 

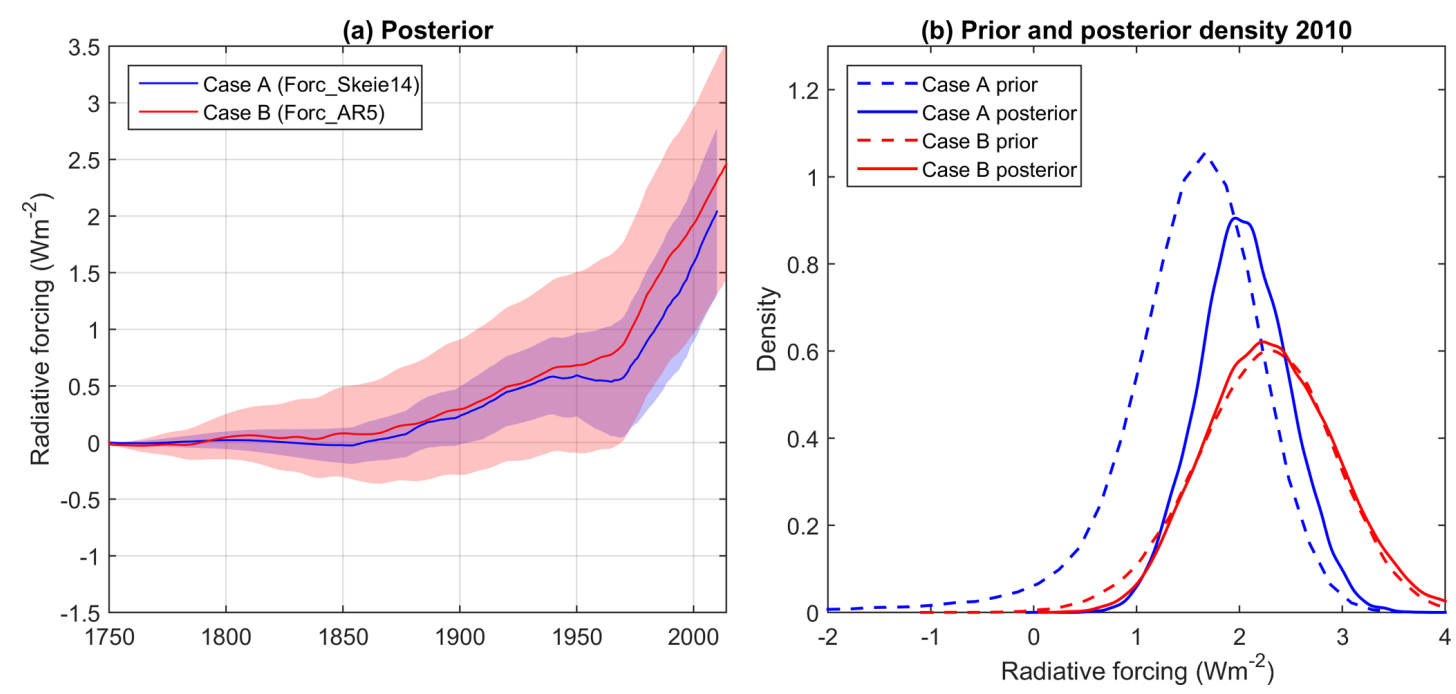

Figure 3. Posterior distribution of time series (a) and prior (dashed) and posterior (solid) probability density function (PDF) in 2010 (b) for anthropogenic forcing. The shaded areas in panel (a) represent the $90 \%$ CI.

dicates that the method and observational data are more in accordance with the new prior than the old one. The same holds for the total forcing (Fig. S4). The $90 \%$ CI for the posterior anthropogenic forcing was 1.3 to $2.8 \mathrm{~W} \mathrm{~m}^{-2}$ in case A compared to 1.3 to $3.4 \mathrm{~W} \mathrm{~m}^{-2}$ in case $\mathrm{B}$. The upper limit of the $90 \% \mathrm{CI}$ is shifted to larger values. The most uncertain part of the forcing time series is associated with aerosols. The difference between the two forcing priors is mainly due to a much weaker aerosol forcing in Forc_AR5 than in Forc_Skeie14 (compare the two dashed-dotted bars in Fig. 4a). While the posterior aerosol forcing was shifted to smaller negative values in case $\mathrm{A}$, the prior and posterior for aerosol forcing are similar in case B (Fig. 4b). A relatively weak aerosolcloud interaction as included in Forc_AR5 is consistent with the recent findings in Malavelle et al. (2017) on how sulfate aerosols from volcanic emissions influences clouds.

The ERFs in AR5 are based on an assessment of several studies reflecting improved knowledge of the forcing mechanisms compared to the one-model RF results used in Skeie14. The new ERFs gave a better posterior estimate of GMST (Fig. 2) and reduced change from prior to posterior forcing (Fig. 3). Note that the number of forcing time series that can be combined was 18 in Skeie14, including 3 time series for volcanic and 8 for aerosols, compared to only 1 time series for each of these forcing mechanisms in Forc_AR5 (Table S2). This gives less flexibility in the time development of the forcing in case B compared to case A; however, the GMST change is better reproduced in the 1980s-1990s using Forc_AR5 compared to Forc_Skeie14.

Ultimately, global climate change is governed by the radiative imbalance at the top of the atmosphere (TOA) and modulated by the internal variability. Forcing by greenhouse gases and aerosols as well as albedo changes, feedback processes and the radiative responses to temperature changes determine this imbalance. With a positive net imbalance at TOA, energy accumulates in the Earth system, mainly as increasing OHC (Church et al., 2011). Since OHC is the dominant energy storage in the system, these data series have profound influ-

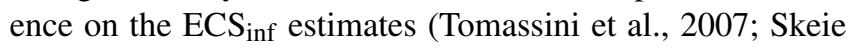
et al., 2014; Aldrin et al., 2012; Johansson et al., 2015). In case $\mathrm{B}$, we have extended our use of $\mathrm{OHC}$ data, so in addition to the three $\mathrm{OHC}$ data series above $700 \mathrm{~m}$, we have included the ORAS4 data above and below $700 \mathrm{~m}$ (Table 1) as two separate data sources. Including the deep-ocean $\mathrm{OHC}$ data gives a stronger constraint on the overall accumulation of heat in the system, and the posterior estimates of the parameters of $\boldsymbol{\theta}$ that determine the vertical transport of heat in the ocean - the effective diffusivity and the upwelling velocity - increase by 44 and $31 \%$, respectively. Having separate data series for the two ocean layers also provides information that influences the balance between negative (by aerosols) and positive forcings, since these forcings have different evolution over time (cf. Sect. 4.1).

In Fig. 5 the observed and fitted OHC for cases A and B are shown. Including data on OHC change below $700 \mathrm{~m}$ increases the total heat uptake. The increase in the fitted $\mathrm{OHC}$ above $700 \mathrm{~m}$ over the last decade is larger in case B compared to case A. In case B the increase in the fitted $\mathrm{OHC}$ above $700 \mathrm{~m}$ is larger than the observational data, while below $700 \mathrm{~m}$, the observed OHC increase is higher than the fitted one (Fig. 5). This is to be expected since the parameters of $\boldsymbol{\theta}$ do not change over time. Thus, the observed rapid change in $\mathrm{OHC}$ below $700 \mathrm{~m}$ over the last years with corresponding slower warming above $700 \mathrm{~m}$ is attributed to long-term internal variability (a part of the $n_{t}$ term) in the model (Fig. S5cd). Note that the Ishii and Kimoto series is outside the $90 \%$ CI. The reason is that the assumed observational errors for all series are much larger back in time than in the recent 


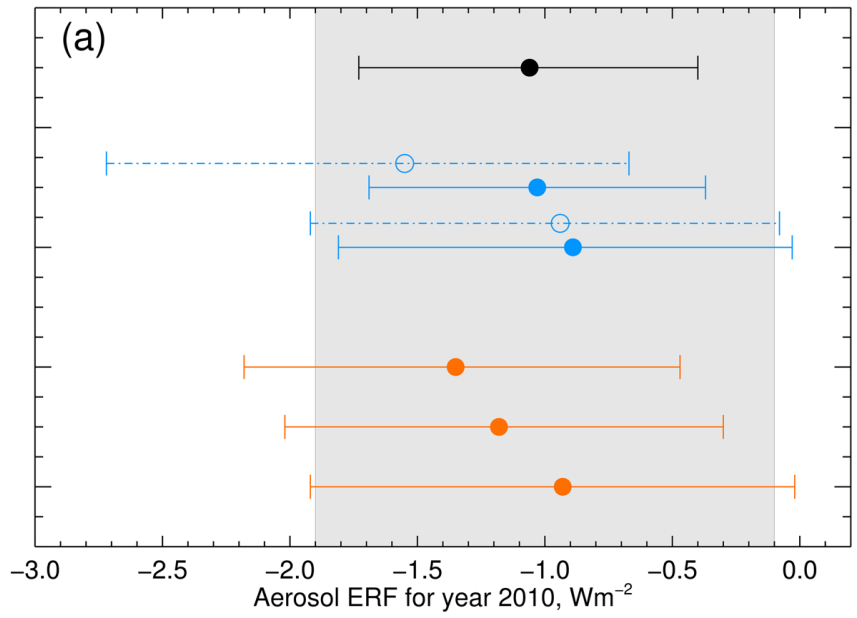

Main analysis Skeie et al. (2014)

A: Main analysis Skeie et al. (2014) refined

B: Main analysis (this study)

C: As B but total $\mathrm{OHC}$ (four series)

D: Total OHC (one series)

E: As $B$ but data from 1950
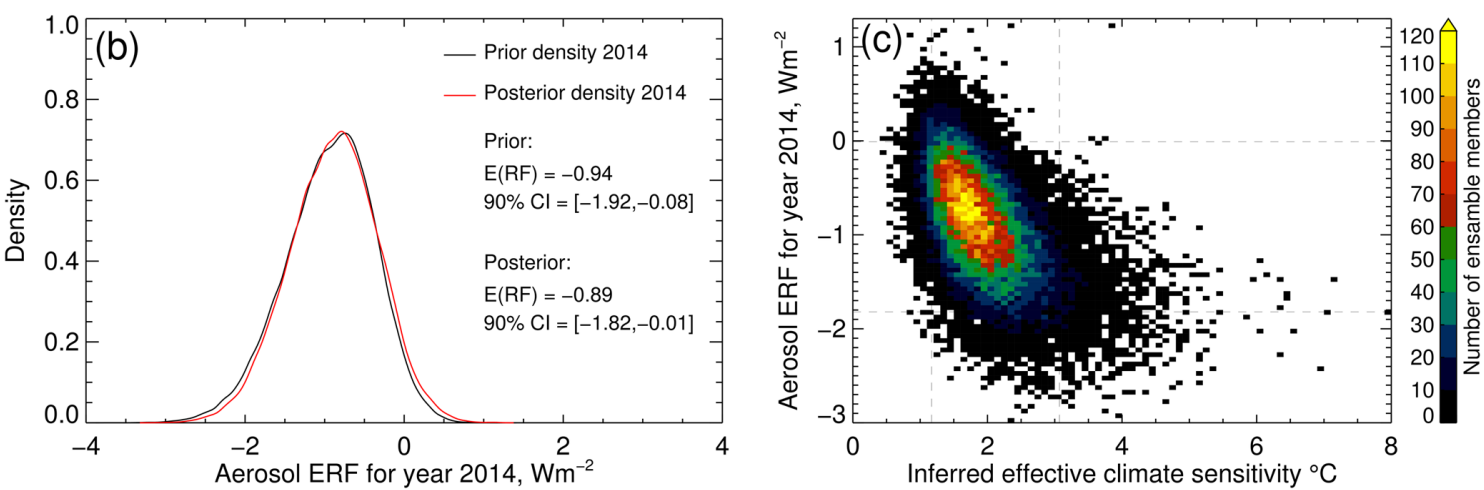

Figure 4. Posterior $90 \%$ CI for aerosol ERF in 2010 for the different analyses in this study (a). The estimated posterior mean is indicated by a dot. The two sets of priors used are shown as dash-dotted bars with the mean value as an open circle. The IPCC AR5 $90 \%$ probability range for aerosol ERF is presented as gray shading. The prior and posterior probability density function (PDF) of aerosol ERF in 2014 in case B are shown in (b). Red color is for the posterior distributions, and the black line is for the prior distribution. Panel (c) shows the relationship between $\mathrm{ECS}_{\text {inf }}$ and aerosol ERF for case B. The posterior $90 \% \mathrm{CI}$ is indicated by dashed lines.

years (see Appendix A). Therefore, the various data series are aligned quite closely to each other in recent years, and since the Ishii and Kimoto series has a much weaker trend than the others, it lies above the $90 \% \mathrm{CI}$ in the first part of the data history.

The update of the $\mathrm{ECS}_{\text {inf }}$ from case A to B was done stepwise in four steps (Fig. S1f, g, $i$ and j). The new ERFs were first implemented. The posterior forcing is much closer to the prior using Forc_AR5 instead of Forc_Skeie14, and the fit to the GMST in the 1980s-1990s also improved with a decrease in the root mean square error between 1980 and 1999 from 0.12 to $0.087^{\circ} \mathrm{C}$ compared to case $\mathrm{A}$. The stronger forcing resulted in a shift of the $\mathrm{ECS}_{\text {inf }}$ estimate to lower values (Fig. S1f vs. e), with an $\mathrm{ECS}_{\text {inf }}$ mean value of $1.5^{\circ} \mathrm{C}(90 \%$ CI $0.9-2.3^{\circ} \mathrm{C}$ ). So far, only $\mathrm{OHC}$ data in the upper $700 \mathrm{~m}$ were used, leaving the model unconstrained with respect to the heating of the deeper ocean.

We then included the ORAS4 data above and below $700 \mathrm{~m}$ as two separate data sources. Similar to Johansson et al. (2015) we found that including the OHC change be- low $700 \mathrm{~m}$ increases the total heat uptake and thus the mean value of $\mathrm{ECS}_{\text {inf }}$ from 1.5 to $1.7^{\circ} \mathrm{C}$ (Fig. S1g vs. f). The $90 \%$ $\mathrm{CI}$ shifted to larger values ranging from 1.0 to $2.8^{\circ} \mathrm{C}$.

The last two steps to update the $\mathrm{ECS}_{\text {inf }}$ estimate from case A to case B were to use the most recent version of the data prior to 2010 and to extend the data series used from 2010 to 2014 (Table 1). Some of the observational data series have been updated by the data suppliers, so first we use refined data up to 2010 before we extend the data series to 2014 (cf. Appendix B). Using the refined data up to 2010, the estimated mean $\mathrm{ECS}_{\text {inf }}$ increased from 1.7 to $2.0^{\circ} \mathrm{C}$ (Fig. S1i) and the $90 \% \mathrm{CI}$ was shifted again to larger values ranging from 1.1 to $3.3^{\circ} \mathrm{C}$. Further, when the data series were extended from 2010 to 2014, the upper bound of the $90 \%$ CI decreased from 3.3 to $3.1{ }^{\circ} \mathrm{C}$ while the lower bound remained unchanged and the mean estimate slightly reduced (Fig. S1j).

In total, the changing from case A to case B did not change

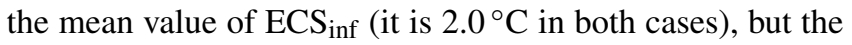
$90 \% \mathrm{CI}$ was reduced from $1.0-3.4$ to $1.2-3.1^{\circ} \mathrm{C}$. The reduc- 


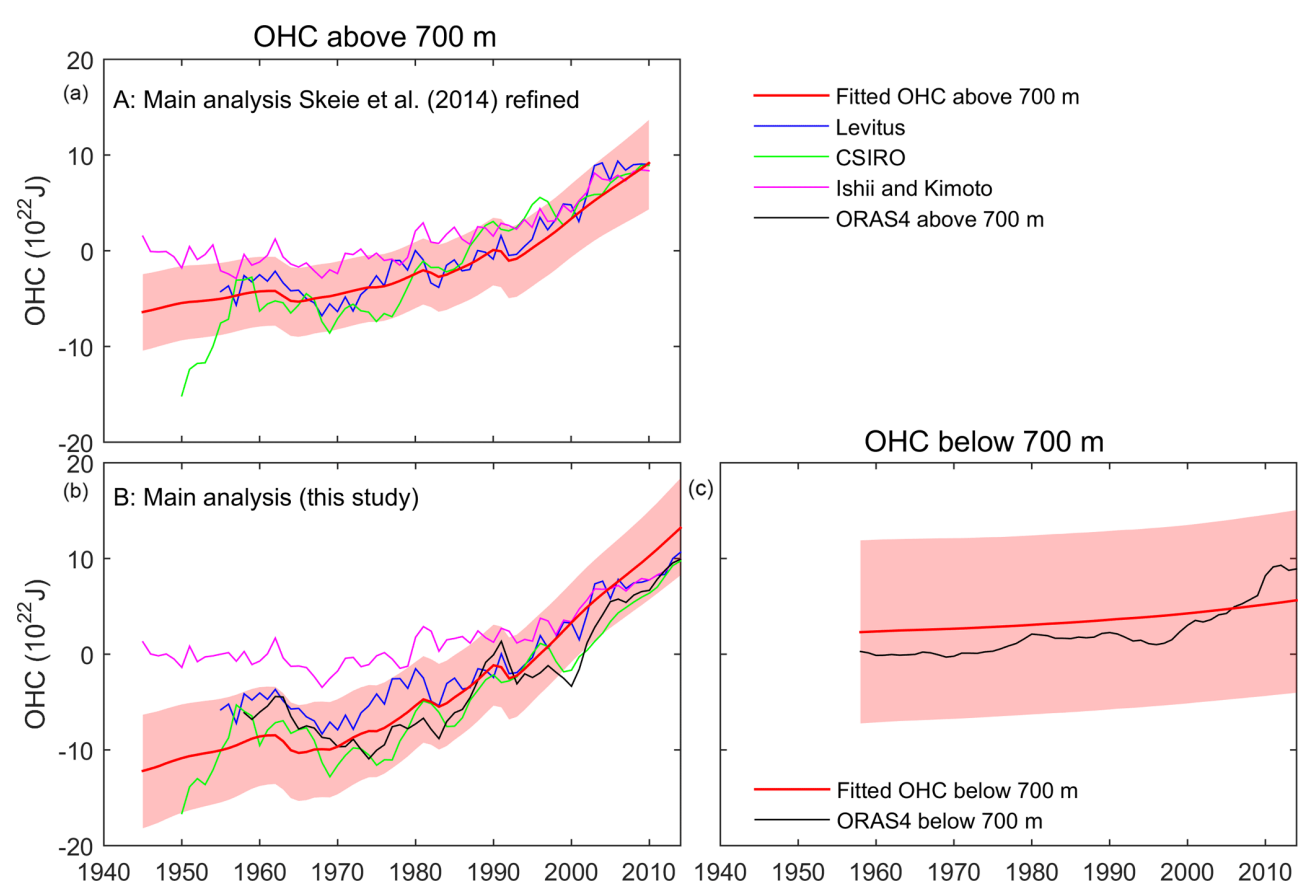

Figure 5. Observed and fitted (posterior mean) values for the OHC for case A (a) and case B (b, c). The shaded areas indicate the $90 \%$ CI. Left-hand side: upper $700 \mathrm{~m}$. Right-hand side: below $700 \mathrm{~m}$ if data are included in the analysis.

tion in ECS $_{\text {inf }}$ in the first step of the update is more or less counteracted by the subsequent steps.

\section{Sensitivity tests - the use of input data}

We now investigate possible causes of differences in observationally based ECS inf estimates due to the use of input data. We analyze the impacts of different usage of the $\mathrm{OHC}$ data (cases $C$ and $D$ ) and the treatment of uncertainties in the GMST data (case E).

\subsection{The role of the use of $\mathrm{OHC}$ data}

The vertical transport of heat in the SCM (with 40 vertical layers) is quite simple. Turbulent diffusion mixes heat down from the surface, while downwelling transports heat directly to the deepest layer, i.e., no detrainment to intermediate layers (Aldrin et al., 2012). Therefore, it is of interest to investigate a constraint of the model with $\mathrm{OHC}$ data for the total depth of the ocean instead of above and below $700 \mathrm{~m}$. In case $\mathrm{C}$ we do not separate the $0-700 \mathrm{~m}$ from the deeper ocean. We use four datasets for total $\mathrm{OHC}$ by adding the ORAS4 below $700 \mathrm{~m}$ data to each of the four $\mathrm{OHC}$ above $700 \mathrm{~m}$ estimates. Merging the $\mathrm{OHC}$ above and below $700 \mathrm{~m}$ (case $\mathrm{C}$ ) results in a substantial decrease in the posterior ERF from 2.5 to $1.8 \mathrm{~W} \mathrm{~m}^{-2}$ (Fig. S6b-c) and an increase in the $\mathrm{ECS}_{\text {inf }}$ estimate from a mean value of $2.0^{\circ} \mathrm{C}$ (median $1.9^{\circ} \mathrm{C}$ ) to $3.2^{\circ} \mathrm{C}$ (median $2.9^{\circ} \mathrm{C}$ ) (Fig. 1a). Without the separate constraint on the $\mathrm{OHC}$ above and below $700 \mathrm{~m}$, the posterior warming of the ocean increases faster (compared to case B) over the last 20 years (Fig. 6). This is mainly caused by enhanced warming in the upper $700 \mathrm{~m}$ (Fig. 7). This allows for a stronger negative ERF estimate for aerosols (Fig. 4a). While the prior and posterior radiative forcing in case $\mathrm{B}$ is similar, in case $\mathrm{C}$ the posterior aerosol ERF is shifted to lower values (Fig. 4a) and the posterior net forcing is shifted towards lower values (Figs. 4a and S6c) and hence a higher estimated ECS $_{\text {inf }}$ (Fig. 1) compared to case B. This anticorrelation between aerosol forcing and $\mathrm{ECS}_{\text {inf }}$ is illustrated in Fig. $4 \mathrm{c}$ for case B. However, the observations show a stronger recent increase in heat in the deep ocean (cf. Sect. 3) and not in the upper $700 \mathrm{~m}$, so this test where this information is not used is likely to overestimate the aerosol forcing strength and hence

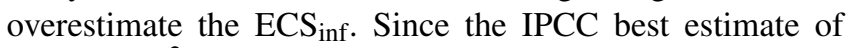
$-0.9 \mathrm{~W} \mathrm{~m}^{-2}$ was published in 2013 for aerosols ERF, studies point towards weak aerosol-cloud interaction (Gordon et al., 2016; Malavelle et al., 2017; Toll et al., 2017). These recent studies indicate that there is no firm evidence to revise the IPCC AR5 aerosol ERF best estimate yet. We therefore keep case B as our best estimate, since having separate data series for the two ocean layers provides information that constrains the balance between negative and positive forcings due to their different time evolution.

A unique feature with our method is that we use data from more than one observational dataset. It is obvious that, as long as the various data series for the same quantity (here OHC above $700 \mathrm{~m}$ ) differ, it is easier to fit a model to one data series, thus giving less uncertainty in the posterior esti- 


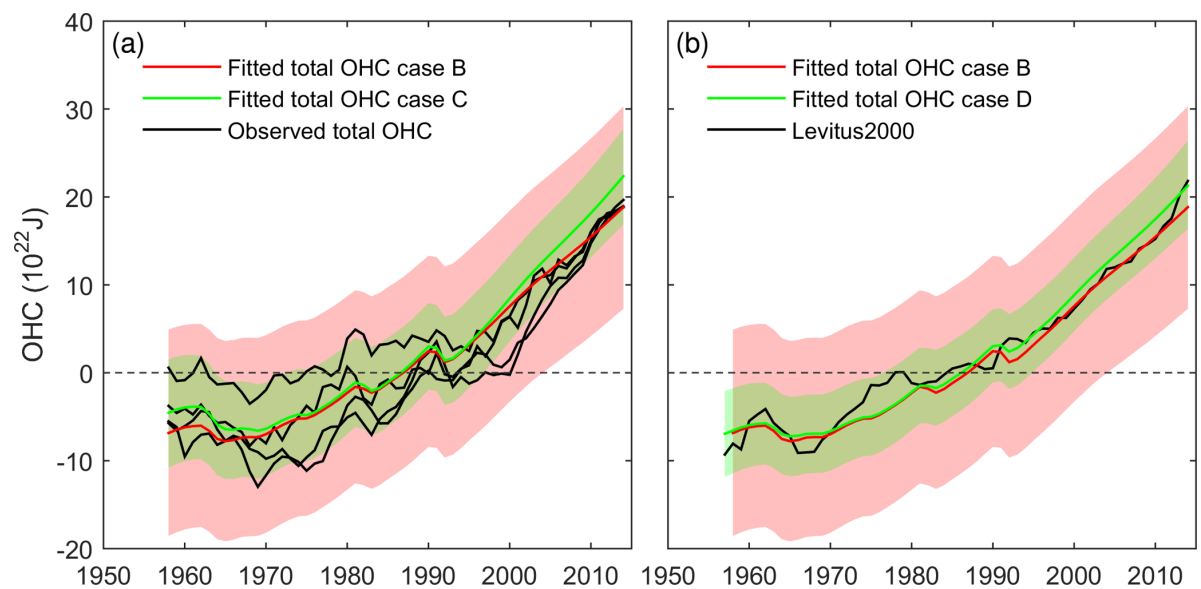

Figure 6. Observed and fitted (posterior mean) total $\mathrm{OHC}$ using several $\mathrm{OHC}$ datasets (case $\mathrm{B}$ : separate $\mathrm{OHC}$ data above and below $700 \mathrm{~m}$; case C: merge $\mathrm{OHC}$ data above and below $700 \mathrm{~m}$; a) and using only one dataset for the total OHC (case D; b). The shaded areas indicate the $90 \%$ CI.

(a) Posterior OHC above $700 \mathrm{~m}$

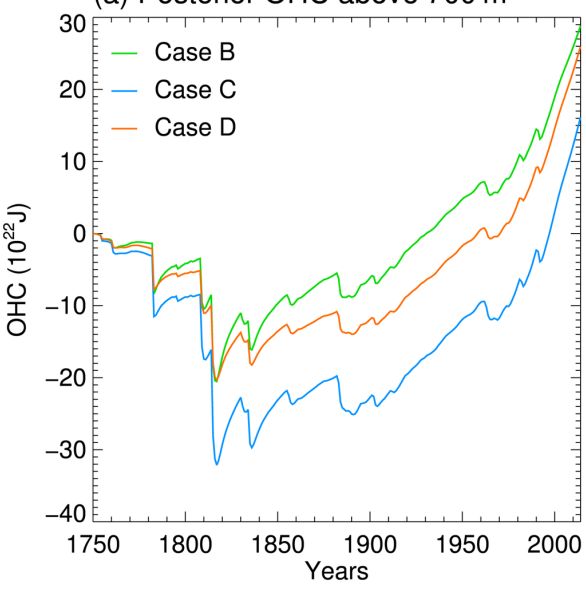

(b) Posterior $\mathrm{OHC}$ below $700 \mathrm{~m}$

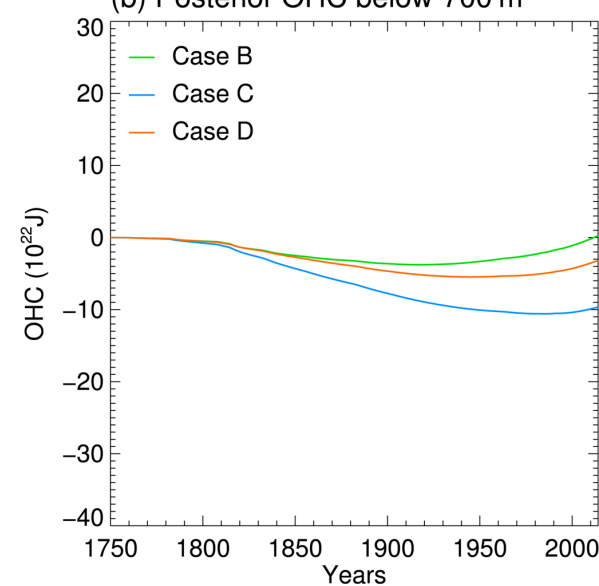

Figure 7. Posterior mean (solid lines) of the output from the deterministic SCM for OHC above $700 \mathrm{~m}$ (a) and below $700 \mathrm{~m}$ (b) for cases B, $\mathrm{C}$ (total $\mathrm{OHC}$ four series) and $\mathrm{D}$ (total $\mathrm{OHC}$ one series).

mates. In case D we test the effect of using one alternative time series for OHC. We choose to use the Levitus2000 time series, which is the same OHC data as used in Johansson et al. (2015). The pentadal heat content is used from 1955 to 2012, treated as annual observations and extended to 2014 using the yearly $\mathrm{OHC}$ data for the upper $2000 \mathrm{~m}$ from the same data source. We use the $\mathrm{OHC}$ data for the upper $2000 \mathrm{~m}$ as they were data for the total OHC. Observed energy stored below $2000 \mathrm{~m}$ is not included in the estimation, and hence the ECS $_{\text {inf }}$ might be underestimated. Energy stored below $2000 \mathrm{~m}$ is uncertain. Purkey and Johnson (2010) found an increase in OHC in the abyssal and deep Southern Ocean in the 1990s and 2000s based on sparse observations from ships, but it is not clear if this is a long-term trend. Llovel et al. (2014) could not detect a deep-ocean (below $2000 \mathrm{~m}$ ) contribution to sea level rise and energy budget between 2005 and 2013 using ocean observations and satellite measurements; however, the uncertainties are large.

As in case $\mathrm{C}$, we do not separate the $\mathrm{OHC}$ data above and below $700 \mathrm{~m}$. Quite similar to case $\mathrm{C}$, there is a more rapid increase in the posterior estimate of total OHC (Fig. 6) compared to case $\mathrm{B}$; the increased warming is mostly in the upper $700 \mathrm{~m}$ (Fig. 7), and the posterior forcing is shifted to lower values than in the prior (Figs. 4a and S6d). In case D the estimated mean $\mathrm{ECS}_{\text {inf }}$ is $2.8^{\circ} \mathrm{C}$ (median $2.6^{\circ} \mathrm{C}, 90 \%$ CI 1.5 $4.6^{\circ} \mathrm{C}$ ) (Fig 1a, case F). This is higher than in case B, but lower than for case $\mathrm{C}$.

The estimated total $\mathrm{OHC}$ has a narrower range when $\mathrm{OHC}$ above and below $700 \mathrm{~m}$ are merged (Fig. 6a). The range is also narrower in case $\mathrm{D}$ than in case $\mathrm{C}$. As expected, using several data series for $\mathrm{OHC}$ (case B: 5 ; case C: 4; case D: 1) increases the posterior observational error. Note that the magnitude of the observational errors is estimated (Aldrin et 
al., 2012; Skeie et al., 2014). In case D, the posterior standard deviation of the observed $\mathrm{OHC}$ is similar to the reported standard deviation (Fig. S8), while when using several OHC time series, the posterior standard deviation is larger (Fig. S7) and arguably more correct than reported due to the large variability among the datasets (Appendix A). Hence, larger uncertainties in the observed $\mathrm{OHC}$ data result in larger uncertainties in the estimated $\mathrm{OHC}$.

Johansson et al. (2015) used the same $\mathrm{OHC}$ data series as in our case D and a similar method; however, their $90 \%$ CI for the OHC in the upper $2000 \mathrm{~m}$ (their Fig. S5) is even narrower. This might not only be due to the use of one $\mathrm{OHC}$ dataset. While we estimate the magnitude of the observational error, Johansson et al. (2015) use the error given by the OHC data provider. In Johansson et al. (2015) the estimated uncertainties in $\mathrm{OHC}$ were smaller than the given observational uncertainties (their Fig. S5). The narrower ECS inf $_{\text {- }}$ range may primarily be because Johansson et al. (2015) assumed very small measurement errors in the most informative data $(\mathrm{OHC})$; secondly, they ignored time correlation in observational errors and did not take into account long-term internal variability to the same degree as in our method.

To sum up, using several observational series (and estimated observational errors) increases the estimated observational errors to more realistic values, since data series are not well correlated and hence increase the range of estimated OHC with implications for estimated $\mathrm{ECS}_{\text {inf }}$.

\subsection{The role of uncertainty estimates in the temperature series}

The prior standard deviation for the surface temperature data is quite different among the datasets (Fig. S7a). The NCDC data have 3 to 5 times larger standard error prior to 1950 compared to after 1950, while it is more constant back to the 19th century for the three other datasets.

To investigate this, we reestimated our model using data only after 1950 , which is equivalent to assuming a very large uncertainty prior to 1950 . The estimated magnitude of the ENSO signal increases (Fig. S5a-b) since the data series are more correlated in the latter part of 20th century. For temperature, the model fits the observations of GMST well, but with a larger $90 \%$ CI range (Fig. 2), and the observed NH and SH temperatures are well within the $90 \% \mathrm{CI}$ of the

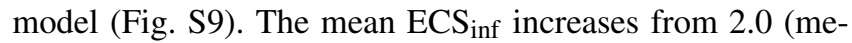
dian $1.9^{\circ} \mathrm{C}$ ) to $2.2^{\circ} \mathrm{C}$ (median $2.1^{\circ} \mathrm{C}$ ), and the upper $90 \%$ CI limit increases from 3.1 to $3.8^{\circ} \mathrm{C}$ (Fig. 1a, case E vs. B). The mean TCR increases from 1.4 to $1.5^{\circ} \mathrm{C}$ and the $90 \% \mathrm{CI}$ is shifted slightly to lower values compared to the range from IPCC by $0.1{ }^{\circ} \mathrm{C}$ (Fig. 1b).

Johansson et al. (2015) used only the NCDC data for GMST; thus, the data prior to 1950 were given little weight when fitting the model. Our ENSO signal is now (case E) of a similar magnitude as in Johansson et al. (2015) (their Fig. 1b). The ECS $S_{\text {inf }}$ uncertainty in this study is still larger, and our mean value is slightly higher than their lower limit of $2{ }^{\circ} \mathrm{C}$.

Excluding data before 1950 also excludes the late 19thcentury period with a large volcanic eruption where the signal in the GMST data is small and quite uncertain (Santer et al., 2016). Santer et al. (2016) argued that the method in Johansson et al. (2015) down-weights the volcanic forcing due to the small response of the Krakatau eruption in the temperature data. Johansson et al. (2016) responded that the observational uncertainty was large, so the GMST data at that time will have a limited effect. In our results, excluding observations before 1950, the GMST response following the Pinatubo eruption in 1991 increases (Fig. 2) and is similar to observations due to the larger ENSO signal and stronger posterior volcanic signal.

In the early period, the aerosol forcing had a larger relative contribution to total ERF causing a more uncertain forcing trend in the early period. Uncertainty in the temporal trend of the forcing is not included, and better representation of forcing uncertainties than the scaling approach is needed (Tanaka et al., 2009). Omitting data before 1950 (case E), when the net forcing is more uncertain (Stevens, 2013), makes it easier to fit the model to observations, but the uncertainty in estimated ECS $_{\text {inf }}$, TCR and GMST and increases (Figs. 1 and 2).

\section{Discussions and conclusions}

Causes of differences in observationally based estimates of $\mathrm{ECS}_{\text {inf }}$ due to the use of input data are analyzed, and an updated $\mathrm{ECS}_{\text {inf }}$ estimate is presented using our Bayesian estimation model. Adding observational data from 2011 to 2014 and $\mathrm{OHC}$ data below $700 \mathrm{~m}$ and replacing forcing data with IPCC AR5 ERFs, the $\mathrm{ECS}_{\text {inf }}$ posterior mean was $2.0^{\circ} \mathrm{C}$ (median $1.9{ }^{\circ} \mathrm{C}, 90 \% \mathrm{CI} 1.2-3.1^{\circ} \mathrm{C}$ ). The mean value is similar and the range is slightly narrower than the refined Skeie14 estimated (Fig. 1 case B vs. A). The mean ECS inf estimate is larger than in Skeie14. Although the estimate in cases A and $B$ is quite similar, the ECS $_{\text {inf }}$ estimate shifted to lower values when Forc_AR5 replaced Forc_Skeie14 (from a mean $\mathrm{ECS}_{\text {inf }}$ estimate of 2.0 to $1.5^{\circ} \mathrm{C}$ ), and it shifted to larger values when $\mathrm{OHC}$ data below $700 \mathrm{~m}$ were included (to a mean $\mathrm{ECS}_{\text {inf }}$ value of $\left.1.7^{\circ} \mathrm{C}\right)$. The $\mathrm{ECS}_{\text {inf }}$ estimate was very sensitive to the forcing data used, and we showed that the ECS inf $_{\text {f }}$ estimate was also sensitive to the assumed uncertainties in the GMST data (case E: $\mathrm{ECS}_{\text {inf }}$ mean value increased from 2.0 to $2.2^{\circ} \mathrm{C}$ ) and how the $\mathrm{OHC}$ data were treated (cases $\mathrm{C}$ and $\mathrm{D}$, with mean $\mathrm{ECS}_{\text {inf }}$ of 3.2 and $2.8^{\circ} \mathrm{C}$, respectively).

Bayesian methods have recently been reviewed by Annan (2015) and Bodman and Jones (2016), and limitation by assuming constant sensitivity over time, the role of the $\mathrm{ECS}_{\text {inf }}$ prior distribution and equal efficacy for different forcings have been discussed. Implementing an alternative prior for $\mathrm{ECS}_{\text {inf }}$ as in Skeie14, where $1 / \mathrm{ECS}_{\text {inf }}$ is uniformly 
distributed, shifted the mean $\mathrm{ECS}_{\text {inf }}$ to lower values from $2.0^{\circ} \mathrm{C}$ (median $1.9^{\circ} \mathrm{C}, 90 \% \mathrm{CI} 1.2-3.1^{\circ} \mathrm{C}$ ) to $1.6^{\circ} \mathrm{C}$ (median $1.6^{\circ} \mathrm{C}, 90 \% \mathrm{CI} 0.97-2.5^{\circ} \mathrm{C}$ ). The $\mathrm{ECS}_{\text {inf }}$ estimate is sensitive to the prior; however, one could argue against this alternative prior because it has a high probability of low climate sensitivities that may not be realistic, with $76 \%$ probability for $\mathrm{ECS}_{\text {inf }}$ being lower than the pure black-body radiation sensitivity of $1.1^{\circ} \mathrm{C}$ (Aldrin et al., 2012; Skeie et al., 2014). Recently, studies have suggested that assuming equal efficacy for all forcings biases the ECS estimate low (Marvel et al., 2015; Shindell et al., 2015) even when ERFs are used. In our approach, the efficacy is implicitly included in the forcing uncertainty and thus accounted for. However, if we apply an efficacy of 1.5 for ozone, surface albedo, BC on snow and aerosols, which is the efficacy found in the analysis of Shindell (2014), the probability density function of the ECS is shifted to larger values (Fig. S11), with a $90 \% \mathrm{CI}$ ranging from 1.2 to $3.7^{\circ} \mathrm{C}$.

The fit to the temperature data in the 1980s and 1990s improved using Forc_AR5 instead of Forc_Skeie14, indicating that the forcing trend over this period is better represented in Forc_AR5 compared to Forc_Skeie14. The trend in the forcing is more uncertain in the first half of the 20th century due to less dominance of $\mathrm{CO}_{2}$, and in our method the same relative uncertainty for the prior forcing is used over the entire time period. A sensitivity simulation omitting observations before 1950 , similar to making these observations very uncertain, gave better representation of the GMST in the latter part of the 20th century and an increased mean ECS $S_{\text {inf }}$. Future work should include uncertainties in the temporal development of the forcing, and there is a clear need for an international effort to establish forcing time series, using a consistent forcing definition and allowing for uncertainties in emissions to give a better representation of the temporal uncertainties.

Including OHC data below $700 \mathrm{~m}$ shifted the $\mathrm{ECS}_{\text {inf }}$ to higher values. The estimated $\mathrm{ECS}_{\mathrm{inf}}$ was found to be very sensitive to how the $\mathrm{OHC}$ data were used. Including four OHC time series but merging the data above and below $700 \mathrm{~m}$ (case $\mathrm{C}$ ), the $\mathrm{ECS}_{\text {inf }}$ mean value increased from 2.0 to $3.2^{\circ} \mathrm{C}$. The probability of $\mathrm{ECS}_{\text {inf }}$ above $4.5^{\circ} \mathrm{C}$ increased to $13 \%$, values that are practically excluded in our main estimate (case B). Previous studies have used total-column OHC data, and due to the simple representation of the ocean one can argue that this might be more appropriate. However, in case $\mathrm{C}$ most of the recent increase in $\mathrm{OHC}$ in the model occurred in the uppermost $700 \mathrm{~m}$, allowing a stronger aerosol cooling (Fig. 4a) and hence a larger $\mathrm{ECS}_{\text {inf }}$, while the observations indicate that the ocean was warming mainly be- low $700 \mathrm{~m}$. Using only the total-column OHC might therefore overestimate the aerosol forcing strength and hence the

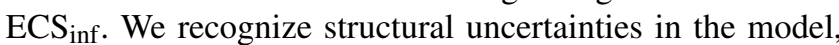
and a multi-model intercomparison of observational methods using identical input data would be of great value to investigate these uncertainties.

Using only the Levitus2000 series for OHC for the totalocean column (case D), the $\mathrm{ECS}_{\text {inf }} 90 \% \mathrm{CI}$ was shifted to lower values with a range of $1.5-4.6^{\circ} \mathrm{C}$ and the range shrunk compared to case $\mathrm{C}$. The historical measurements of ocean temperatures are sparse (Abraham et al., 2013), with large differences between the datasets. The temporal structure of the reported uncertainties differs, and the full uncertainties are often not assessed. Hence, relying on only one $\mathrm{OHC}$ series and its reported uncertainty may underestimate the observational uncertainties and hence overestimate the certainties in the estimated $\mathrm{OHC}$ with implications for the $\mathrm{ECS}_{\mathrm{inf}}$ estimate.

Recent studies indicate that the upper-ocean warming is underestimated due to the gap-filling methods (Durack et al., 2014; Li-Jing et al., 2015), in which case the ECS $S_{\text {inf }}$ will also be underestimated. When refining historical OHC estimates, not only the best value, but also the uncertainty is crucial for observationally based $\mathrm{ECS}_{\text {inf }}$ estimation.

Other priorities are to improve the GMST series, including uncertainties - not only for the recent trend (Karl et al., 2015; Cowtan and Way, 2014) but also for earlier time periods. Assuming a very large uncertainty prior to 1950 , the GMST fit improved and the ECS $\mathrm{Sinf}_{\mathrm{in}}$ mean increased while the estimated uncertainty ranges increased.

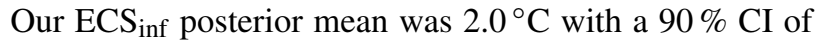
1.2 to $3.1^{\circ} \mathrm{C}$. This is consistent with a mean ECS of $2.9^{\circ} \mathrm{C}$ (Armour, 2017), which compares reasonably well with climate model estimates (Andrews et al., 2012; Forster et al., 2013). A final remark is that it is not obvious that the true ECS is a more relevant metric for the climate sensitivity than the ECS $_{\text {inf }}$ in a policy context (i.e., the Paris Agreement). The United Nations Framework Convention on Climate Change (UNFCCC) has not adopted a predefined definition of GMST and the stronger long-term feedbacks found in an analysis of CMIP5 simulations (Proistosescu and Huybers, 2017) operate on a timescale longer than the timescale for reaching $2{ }^{\circ} \mathrm{C}$.

Data availability. Several publicly available datasets were used in this study. The specific references to the data sources are given in Table 1. Model outputs are available upon request. 


\section{Appendix A: Refinement of Skeie14}

A few updates/corrections to Skeie14 (Fig. S1a) had to be made prior to the analyses presented in this study. In the Skeie14 study, the standard error of observed OHC above $700 \mathrm{~m}$ for two out of the three series was constant in time, while for the third dataset the standard error decreased with time. Due to the limited observational data back in history (e.g., Abraham et al., 2013), it is reasonable to assume that the shape of the standard error of observed global OHC increases back in time, as for the CSIRO series. Therefore, we now assume a common observational uncertainty temporal profile for OHC above $700 \mathrm{~m}$ equal to CSIRO for all the OHC time series (Fig. S1b). Note that the magnitude of the observational errors are estimated in our approach (Aldrin et al., 2012; Skeie et al., 2014); i.e., we account for the possibilities that the reported observational errors may be biased upward or downwards compared to the real observational errors.

In fact, the results from Skeie et al. (2014, Appendix B) indicated that the reported standard errors for the Levitus and the Ishii and Kimoto OHC series were too low. We have investigated this further by the following simple analysis.

Let $y_{1 t}$ and $y_{2 t}$ be two different estimates of the true $\mathrm{OHC}$ in year $t$. Then $y_{1 t}=$ "true $\mathrm{OHC} "+e_{1 t}$ and $y_{2 t}=$ "true $\mathrm{OHC} "+e_{2 t}$. Here, $e_{1 t}$ and $e_{2 t}$ are error terms, with reported standard deviations $s_{1 t}$ and $s_{2 t}$, and with true, but unknown standard deviations $\sigma_{1 t}$ and $\sigma_{2 t}$. The difference of the series is $y_{1 t}-y_{2 t}=e_{1 t}-e_{2 t}$, so even if we cannot observe the errors, we can observe their difference. If the two data series are based on more or less the same data, as for the OHC series used here, one can expect that $e_{1 t}$ and $e_{2 t}$ are positively correlated. Then $\operatorname{Var}\left(y_{1 t}-y_{2 t}\right)=\operatorname{Var}\left(e_{1 t}-e_{2 t}\right)<=\left(\sigma_{1 t}^{2}+\sigma_{2 t}^{2}\right)$

We can estimate the average variance of the differences $y_{1 t}-y_{2 t}$ over all time points by $\operatorname{Var}^{\text {obs }}=1 /(n-1) \sum_{t}\left(y_{1 t}-\right.$ $\left.y_{2 t}-m\right)^{2}$, where $m$ is the average of $y_{1 t}-y_{2 t}$ and $n$ is the number of years. This could be compared to the corresponding reported variance under the assumption of uncorrelated errors, by $\operatorname{Var}^{\mathrm{rep}}=1 / n \sum_{t}\left(s_{1 t}^{2}+s_{2 t}^{2}\right)$, and if the reported standard deviations are correct, then the variance ratio Varobs /Varep should be less than or equal to 1. For differences of the Levitus, Ishii and Kimoto and ORAS4 (above $700 \mathrm{~m}$ ) series, the variance ratios are between 2.13 and 3.74 (Table A1), indicating that the reported observational errors for these series are too low, and the real uncertainty may be larger. This is an additional argument for using the CSIRO standard errors for all OHC series.

Another update of Skeie14 that was needed was to use monthly volcanic RF data (Fig. S1c) compared to yearly data in Skeie14. In addition to the three global mean surface temperature (GMST) time series used in Skeie14, another time series for GMST has been published recently (Cowtan and Way, 2014). This time series finds a stronger increasing trend in temperature over the last decade compared to the HadCRUT4 data, due to the method of accounting for the unsam-
Table A1. Variance ratios Var ${ }^{\text {obs }} /$ Var $^{\text {rep }}$ for pairwise differences of OHC series.

\begin{tabular}{llr}
\hline OHC series 1 & OHC series 2 & $\operatorname{Var}^{\text {obs }} / \operatorname{Var}^{\text {rep }}$ \\
\hline CSIRO & Levitus & 0.21 \\
CSIRO & Ishii and Kimoto & 0.43 \\
CSIRO & ORAS4 & 0.17 \\
Levitus & Ishii and Kimoto & 2.13 \\
Levitus & ORAS4 & 3.74 \\
Ishii and Kimoto & ORAS4 & 3.49 \\
\hline
\end{tabular}

pled regions in the world. This data series is now included (Fig. S1d).

Our previous studies showed that the correlation between the observational errors in temperature data was almost uncorrelated with the observational errors in the $\mathrm{OHC}$ data. Therefore, to simplify the numerical computations, we from now on assume that these correlations are exactly zero (Fig. S1e).

The estimated $\mathrm{ECS}_{\text {inf }}$ for each step in the refinement of Skeie14 is presented in Fig. S1a-e.

\section{Appendix B: Extending data up to and including 2014}

When extending the analysis from 2010 to 2014, not all the time series used in the estimation is available up to and including the year 2014. Below is a description of how the different datasets are extended if not available up to 2014.

AR5 ERF: The end year for the forcing time series presented in AR5 is 2011 and has to be extended to 2014. For long-lived greenhouse gases the time series are extended using recent observations of global mean concentrations and the formulas relating concentrations and forcing used in Skeie et al. (2011). Tropospheric ozone, stratospheric ozone, aerosol ERF, land use change, BC on snow and volcanoes are kept constant between 2011 and 2014. Stratospheric water vapor follows methane RF. Contrails $\mathrm{RF}$ is extended using aircraft traffic data (http://airlines. org/dataset/world-airlines-traffic-and-capacity/, last access: March 2015). Solar RF is extended using the PhysikalischMeteorologisches Observatorium Davos (PMOD) composite (Frohlich and Lean, 2004).

CSIRO: Data up to and including 2012 were downloaded. The time series were extended from 2012 to 2014 using the mean rate of change of the other $\mathrm{OHC}$ data. The uncertainty in 2014 and 2013 is set equal to the uncertainty in 2012.

ORAS4: Balmaseda et al. (2013) investigated the time evolution of global $\mathrm{OHC}$ at different depths of the ocean from 1958 to 2009 using the European Centre for Medium-Range Weather Forecasts ocean reanalysis system 4 (ORAS4). Five ensemble members of ORAS4 are generated that sample plausible uncertainties in the wind forcing, observation coverage and the deep ocean. The ORAS4 system runs auto- 
matically in operations, with numerical weather prediction forcing and observations that are not manually quality controlled. The $1 \times 1^{\circ}$ ocean potential temperature up to December 2014 are made available through the APDRC (http: //apdrc.soest.hawaii.edu/datadoc/ecmwf_oras4.php, last access: March 2015) for one ensemble member. The trend in OHC for the total depth and upper $700 \mathrm{~m}$ from 2010 to 2014 based on the one ensemble member is used to extend the corresponding $\mathrm{OHC}$ data for all the five ensemble members from Balmaseda et al. (2013) up to 2014. The data after 2009 are based on the automatic ORAS4 system and are not quality controlled, and the results in this paper using the data after 2009 should be interpreted with caution. The same method is used to extend the ORAS4 data from 2009 to 2010 (Fig. S1gi). From the five ensemble members, the estimate with uncertainty is calculated as the annual average and standard deviation of $\mathrm{OHC}$ above and below $700 \mathrm{~m}$. The standard deviations are modified by smoothing the curve (9-year moving average) since the curve was otherwise very static. 
Supplement. The supplement related to this article is available online at: https://doi.org/10.5194/esd-9-879-2018-supplement.

Author contributions. All authors designed the study and discussed the results; RBS and $\mathrm{MH}$ prepared the data; $\mathrm{MH}$ performed the simulations; RBS and MH made the figures; RBS prepared the paper with contributions from all coauthors.

Competing interests. The authors declare that they have no conflict of interest.

Acknowledgements. This research was partly supported by the Norwegian Research Council under the project EVA - Earth system modeling of climate Variations in the Anthropocene, grant number 229771. We kindly acknowledge the data providers listed in Table 1 for providing the data for the analysis.

Edited by: Valerio Lucarini

Reviewed by: two anonymous referees

\section{References}

Abraham, J. P., Baringer, M., Bindoff, N. L., Boyer, T., Cheng, L. J., Church, J. A., Conroy, J. L., Domingues, C. M., Fasullo, J. T., Gilson, J., Goni, G., Good, S. A., Gorman, J. M., Gouretski, V., Ishii, M., Johnson, G. C., Kizu, S., Lyman, J. M., Macdonald, A. M., Minkowycz, W. J., Moffitt, S. E., Palmer, M. D., Piola, A. R., Reseghetti, F., Schuckmann, K., Trenberth, K. E., Velicogna, I., and Willis, J. K.: A review of global ocean temperature observations: Implications for ocean heat content estimates and climate change, Rev. Geophys., 51, 450-483, https://doi.org/10.1002/rog.20022, 2013.

Aldrin, M., Holden, M., Guttorp, P., Skeie, R. B., Myhre, G., and Berntsen, T. K.: Bayesian estimation of climate sensitivity based on a simple climate model fitted to observations of hemispheric temperatures and global ocean heat content, Environmetrics, 23, 253-271, https://doi.org/10.1002/env.2140, 2012.

Andrews, T., Gregory, J. M., Webb, M. J., and Taylor, K. E.: Forcing, feedbacks and climate sensitivity in CMIP5 coupled atmosphere-ocean climate models, Geophys. Res. Lett., 39, L09712, https://doi.org/10.1029/2012GL051607, 2012.

Andrews, T., Gregory, J. M., and Webb, M. J.: The Dependence of Radiative Forcing and Feedback on Evolving Patterns of Surface Temperature Change in Climate Models, J. Climate, 28, 16301648, https://doi.org/10.1175/jcli-d-14-00545.1, 2015.

Annan, J. D.: Recent Developments in Bayesian Estimation of Climate Sensitivity, Curr. Clim. Change Rep., 1, 263-267, https://doi.org/10.1007/s40641-015-0023-5, 2015.

Armour, K. C.: Energy budget constraints on climate sensitivity in light of inconstant climate feedbacks, Nature Clim. Change, 7, 331-335, https://doi.org/10.1038/nclimate3278, 2017.

Balmaseda, M. A., Trenberth, K. E., and Källén, E.: Distinctive climate signals in reanalysis of global ocean heat content, Geophys. Res. Lett., 40, 1754-1759, https://doi.org/10.1002/grl.50382, 2013.
Bodman, R. W. and Jones, R. N.: Bayesian estimation of climate sensitivity using observationally constrained simple climate models, WIRES Clim. Change, 7, 461-473, https://doi.org/10.1002/wcc.397, 2016.

Bony, S., Stevens, B., Frierson, D. M. W., Jakob, C., Kageyama, M., Pincus, R., Shepherd, T. G., Sherwood, S. C., Siebesma, A. P., Sobel, A. H., Watanabe, M., and Webb, M. J.: Clouds, circulation and climate sensitivity, Nat. Geosci., 8, 261-268, https://doi.org/10.1038/ngeo2398, 2015.

Boucher, O., Randall, D., Artaxo, P., Bretherton, C., Feingold, G., Forster, P., Kerminen, V.-M., Kondo, Y., Liao, H., Lohmann, U., Rasch, P., Satheesh, S. K., Sherwood, S., Stevens, B., and Zhang, X. Y.: Clouds and Aerosols, in: Climate Change 2013: The Physical Science Basis. Contribution of Working Group I to the Fifth Assessment Report of the Intergovernmental Panel on Climate Change, edited by: Stocker, T. F., Qin, D., Plattner, G.-K., Tignor, M., Allen, S. K., Boschung, J., Nauels, A., Xia, Y., Bex, V., and Midgley, P. M., Cambridge University Press, Cambridge, UK and New York, NY, USA, 2013.

Chen, X. and Tung, K.-K.: Varying planetary heat sink led to globalwarming slowdown and acceleration, Science, 345, 897-903, https://doi.org/10.1126/science.1254937, 2014.

Church, J. A., White, N. J., Konikow, L. F., Domingues, C. M., Cogley, J. G., Rignot, E., Gregory, J. M., van den Broeke, M. R., Monaghan, A. J., and Velicogna, I.: Revisiting the Earth's sea-level and energy budgets from 1961 to 2008, Geophys. Res. Lett., 38, L18601, https://doi.org/10.1029/2011gl048794, 2011.

Collins, M., Knutti, R., Arblaster, J. M., Dufresne, J.-L., Fichefet, T., Friedlingstein, P., Gao, X., Gutowski, W. J., Johns, T., Krinner, G., Shongwe, M., Tebaldi, C., Weaver, A. J., and Wehner, M.: Long-term Climate Change: Projections, Commitments and Irreversibility, in: Climate Change 2013: The Physical Science Basis. Contribution of Working Group I to the Fifth Assessment Report of the Intergovernmental Panel on Climate Change, edited by: Stocker, T. F., Qin, D., Plattner, G.-K., Tignor, M., Allen, S. K., Boschung, J., Nauels, A., Xia, Y., Bex, V., and Midgley, P. M., Cambridge University Press, Cambridge, UK and New York, NY, USA, 2013.

Cowtan, K. and Way, R. G.: Coverage bias in the HadCRUT4 temperature series and its impact on recent temperature trends, Q. J. Roy. Meteor. Soc., 140, 1935-1944, https://doi.org/10.1002/qj.2297, 2014.

Domingues, C. M., Church, J. A., White, N. J., Gleckler, P. J., Wijffels, S. E., Barker, P. M., and Dunn, J. R.: Improved estimates of upper-ocean warming and multi-decadal sea-level rise, Nature, 453, 1090-1093, https://doi.org/10.1038/nature07080, 2008.

Durack, P. J., Gleckler, P. J., Landerer, F. W., and Taylor, K. E.: Quantifying underestimates of long-term upperocean warming, Nature Clim. Change, 4, 999-1005, https://doi.org/10.1038/nclimate2389, 2014.

Forster, P. M.: Inference of Climate Sensitivity from Analysis of Earth's Energy Budget, Annu. Rev. Earth Pl. Sc., 44, 85-106, https://doi.org/10.1146/annurev-earth-060614-105156, 2016.

Forster, P. M., Andrews, T., Good, P., Gregory, J. M., Jackson, L. S., and Zelinka, M.: Evaluating adjusted forcing and model spread for historical and future scenarios in the CMIP5 generation of climate models, J. Geophys. Res., 118, 1139-1150, https://doi.org/10.1002/jgrd.50174, 2013. 
Frohlich, C. and Lean, J.: Solar radiative output and its variability: evidence and mechanisms, Astron. Astrophys. Rev., 12, 273320, 2004

Gordon, H., Sengupta, K., Rap, A., Duplissy, J., Frege, C., Williamson, C., Heinritzi, M., Simon, M., Yan, C., Almeida, J., Tröstl, J., Nieminen, T., Ortega, I. K., Wagner, R., Dunne, E. M., Adamov, A., Amorim, A., Bernhammer, A.-K., Bianchi, F., Breitenlechner, M., Brilke, S., Chen, X., Craven, J. S., Dias, A., Ehrhart, S., Fischer, L., Flagan, R. C., Franchin, A., Fuchs, C., Guida, R., Hakala, J., Hoyle, C. R., Jokinen, T., Junninen, H., Kangasluoma, J., Kim, J., Kirkby, J., Krapf, M., Kürten, A., Laaksonen, A., Lehtipalo, K., Makhmutov, V., Mathot, S., Molteni, U., Monks, S. A., Onnela, A., Peräkylä, O., Piel, F., Petäjä, T., Praplan, A. P., Pringle, K. J., Richards, N. A. D., Rissanen, M. P., Rondo, L., Sarnela, N., Schobesberger, S., Scott, C. E., Seinfeld, J. H., Sharma, S., Sipilä, M., Steiner, G., Stozhkov, Y., Stratmann, F., Tomé, A., Virtanen, A., Vogel, A. L., Wagner, A. C., Wagner, P. E., Weingartner, E., Wimmer, D., Winkler, P. M., Ye, P., Zhang, X., Hansel, A., Dommen, J., Donahue, N. M., Worsnop, D. R., Baltensperger, U., Kulmala, M., Curtius, J., and Carslaw, K. S.: Reduced anthropogenic aerosol radiative forcing caused by biogenic new particle formation, P. Natl. Acad. Sci. USA, 113, 12053-12058, https://doi.org/10.1073/pnas.1602360113, 2016.

Hansen, J., Sato, M., Ruedy, R., Lo, K., Lea, D. W., and MedinaElizade, M.: Global temperature change, P. Natl. Acad. Sci. USA, 103, 14288-14293, https://doi.org/10.1073/pnas.0606291103, 2006.

Hansen, J., Ruedy, R., Sato, M., and Lo, K.: Global surface temperature change, Rev. Geophys., 48, Rg4004, https://doi.org/10.1029/2010rg000345, 2010.

Haustein, K., Allen, M. R., Forster, P. M., Otto, F. E. L., Mitchell, D. M., Matthews, H. D., and Frame, D. J.: A real-time Global Warming Index, Sci. Rep., 7, 15417, https://doi.org/10.1038/s41598-017-14828-5, 2017.

Ishii, M. and Kimoto, M.: Reevaluation of historical ocean heat content variations with time-varying XBT and MBT depth bias corrections, J. Oceanogr., 65, 287-299, https://doi.org/10.1007/s10872-009-0027-7, 2009.

Johansson, D. J. A., O’Neill, B. C., Tebaldi, C., and Haggstrom, O.: Equilibrium climate sensitivity in light of observations over the warming hiatus, Nature Clim. Change, 5, 449-453, https://doi.org/10.1038/nclimate2573, 2015.

Johansson, D. J. A., O’Neill, B. C., Tebaldi, C., and Haggstrom, O.: Reply to "Volcanic effects on climate", Nature Clim. Change, 6, 4-5, https://doi.org/10.1038/nclimate2861, 2016.

Karl, T. R., Arguez, A., Huang, B., Lawrimore, J. H., McMahon, J. R., Menne, M. J., Peterson, T. C., Vose, R. S., and Zhang, H.-M.: Possible artifacts of data biases in the recent global surface warming hiatus, Science, 348, 1469-1472, https://doi.org/10.1126/science.aaa5632, 2015.

Kennedy, M. C. and O'Hagan, A.: Bayesian calibration of computer models, J. Roy. Stat. Soc. B, 63, 425-450, 2001.

Knutti, R., Rugenstein, M. A. A., and Hegerl, G. C.: Beyond equilibrium climate sensitivity, Nat. Geosci., 10, 727-736, https://doi.org/10.1038/ngeo3017, 2017.

Levitus, S., Antonov, J. I., Boyer, T. P., Locarnini, R. A., Garcia, H. E., and Mishonov, A. V.: Global ocean heat content 1955-2008 in light of recently revealed instrumentation problems, Geophys.
Res. Lett., 36, L07608, https://doi.org/10.1029/2008g1037155, 2009.

Levitus, S., Antonov, J. I., Boyer, T. P., Baranova, O. K., Garcia, H. E., Locarnini, R. A., Mishonov, A. V., Reagan, J. R., Seidov, D., Yarosh, E. S., and Zweng, M. M.: World ocean heat content and thermosteric sea level change (0-2000 m), 1955-2010, Geophys. Res. Lett., 39, L10603, https://doi.org/10.1029/2012GL051106, 2012.

Li-Jing, C., Jiang, Z., and Abraham, J.: Global Upper Ocean Heat Content Estimation: Recent Progress and the Remaining Challenges, Atmos. Ocean. Sci. Lett., 8, 333-338, https://doi.org/10.3878/aos120150031, 2015.

Llovel, W., Willis, J. K., Landerer, F. W., and Fukumori, I.: Deepocean contribution to sea level and energy budget not detectable over the past decade, Nature Clim. Change, 4, 1031-1035, https://doi.org/10.1038/nclimate2387, 2014.

Lyman, J. M. and Johnson, G. C.: Estimating Global Ocean Heat Content Changes in the Upper $1800 \mathrm{~m}$ since 1950 and the Influence of Climatology Choice, J. Climate, 27, 1945-1957, https://doi.org/10.1175/JCLI-D-12-00752.1, 2013.

Malavelle, F. F., Haywood, J. M., Jones, A., Gettelman, A., Clarisse, L., Bauduin, S., Allan, R. P., Karset, I. H. H., Kristjánsson, J. E., Oreopoulos, L., Cho, N., Lee, D., Bellouin, N., Boucher, O., Grosvenor, D. P., Carslaw, K. S., Dhomse, S., Mann, G. W., Schmidt, A., Coe, H., Hartley, M. E., Dalvi, M., Hill, A. A., Johnson, B. T., Johnson, C. E., Knight, J. R., O'Connor, F. M., Partridge, D. G., Stier, P., Myhre, G., Platnick, S., Stephens, G. L., Takahashi, H., and Thordarson, T.: Strong constraints on aerosol-cloud interactions from volcanic eruptions, Nature, 546, 485-491, https://doi.org/10.1038/nature22974, 2017.

Marvel, K., Schmidt, G. A., Miller, R. L., and Nazarenko, L. S.: Implications for climate sensitivity from the response to individual forcings, Nature Clim. Change, 6, 386-389, https://doi.org/10.1038/nclimate2888, 2015.

Meehl, G. A., Arblaster, J. M., Fasullo, J. T., Hu, A., and Trenberth, K. E.: Model-based evidence of deep-ocean heat uptake during surface-temperature hiatus periods, Nature Clim. Change, 1, 360-364, https://doi.org/10.1038/nclimate1229, 2011.

Meehl, G. A., Hu, A., Arblaster, J. M., Fasullo, J., and Trenberth, K. E.: Externally Forced and Internally Generated Decadal Climate Variability Associated with the Interdecadal Pacific Oscillation, J. Climate, 26, 7298-7310, https://doi.org/10.1175/JCLI-D-1200548.1, 2013.

Morice, C. P., Kennedy, J. J., Rayner, N. A., and Jones, P. D.: Quantifying uncertainties in global and regional temperature change using an ensemble of observational estimates: The HadCRUT4 data set, J. Geophys. Res., 117, D08101, https://doi.org/10.1029/2011JD017187, 2012.

Myhre, G., Shindell, D., Bréon, F.-M., Collins, W., Fuglestvedt, J., Huang, J., Koch, D., Lamarque, J.-F., Lee, D., Mendoza, B., Nakajima, T., Robock, A., Stephens, G., Takemura, T., and Zhang, H.: Anthropogenic and Natural Radiative Forcing, in: Climate Change 2013: The Physical Science Basis. Contribution of Working Group I to the Fifth Assessment Report of the Intergovernmental Panel on Climate Change, edited by: Stocker, T. F., Qin, D., Plattner, G.-K., Tignor, M., Allen, S. K., Boschung, J., Nauels, A., Xia, Y., Bex, V., and Midgley, P. M., Cambridge University Press, Cambridge, UK and New York, NY, USA, 2013. 
Palmer, M. D. and McNeall, D. J.: Internal variability of Earth's energy budget simulated by CMIP5 climate models, Environ. Res. Lett., 9, 034016, https://doi.org/10.1088/1748-9326/9/3/034016, 2014.

Proistosescu, C. and Huybers, P. J.: Slow climate mode reconciles historical and model-based estimates of climate sensitivity, Science Advances, 3, e1602821, https://doi.org/10.1126/sciadv.1602821, 2017.

Purkey, S. G. and Johnson, G. C.: Warming of Global Abyssal and Deep Southern Ocean Waters between the 1990s and 2000s: Contributions to Global Heat and Sea Level Rise Budgets, J. Climate, 23, 6336-6351, https://doi.org/10.1175/2010jcli3682.1, 2010.

Richardson, M., Cowtan, K., Hawkins, E., and Stolpe, M. B.: Reconciled climate response estimates from climate models and the energy budget of Earth, Nature Clim. Change, 6, 931-935, https://doi.org/10.1038/nclimate3066, 2016.

Santer, B., Solomon, S., Ridley, D., Fyfe, J., Beltran, F., Bonfils, C., Painter, J., and Zelinka, M.: Volcanic effects on climate, Nature Clim. Change, 6, 3-4, https://doi.org/10.1038/nclimate2859, 2016.

Schlesinger, M. E., Jiang, X., and Charlson, R. J.: Implication of Anthropogenic Atmospheric Sulphate for the Sensitivity of the Climate System, in: Climate Change and Energy Policy: Proceedings of the International Conference on Global Climate Change: Its Mitigation Through Improved Production and Use of Energy, edited by: Rosen, L. and Glasser, R., American Institute of Physics, New York, USA, 75-108, 1992.

Sherwood, S. C., Bony, S., Boucher, O., Bretherton, C., Forster, P. M., Gregory, J. M., and Stevens, B.: Adjustments in the Forcing-Feedback Framework for Understanding Climate Change, B. Am. Meteorol. Soc., 96, 217-228, https://doi.org/10.1175/BAMS-D-13-00167.1, 2014.

Shindell, D. T.: Inhomogeneous forcing and transient climate sensitivity, Nature Clim. Change, 4, 274-277, https://doi.org/10.1038/nclimate2136, 2014.

Shindell, D. T., Faluvegi, G., Rotstayn, L., and Milly, G.: Spatial patterns of radiative forcing and surface temperature response, J. Geophys. Res., 120, 5385-5403, https://doi.org/10.1002/2014JD022752, 2015.

Skeie, R. B., Berntsen, T. K., Myhre, G., Tanaka, K., Kvalevåg, M. M., and Hoyle, C. R.: Anthropogenic radiative forcing time series from pre-industrial times until 2010, Atmos. Chem. Phys., 11, 11827-11857, https://doi.org/10.5194/acp-11-118272011, 2011.
Skeie, R. B., Berntsen, T., Aldrin, M., Holden, M., and Myhre, G.: A lower and more constrained estimate of climate sensitivity using updated observations and detailed radiative forcing time series, Earth Syst. Dynam., 5, 139-175, https://doi.org/10.5194/esd-5139-2014, 2014.

Smith, T. M. and Reynolds, R. W.: A global merged land-air-sea surface temperature reconstruction based on historical observations (1880-1997), J. Climate, 18, 2021-2036, 2005.

Smith, T. M., Reynolds, R. W., Peterson, T. C., and Lawrimore, J.: Improvements to NOAA's historical merged land-ocean surface temperature analysis (1880-2006), J. Climate, 21, 2283-2296, https://doi.org/10.1175/2007jcli2100.1, 2008.

Stevens, B.: Climate science: Uncertain then, irrelevant now, Nature, 503, 47-48, https://doi.org/10.1038/503047a, 2013.

Tan, I., Storelvmo, T., and Zelinka, M. D.: Observational constraints on mixed-phase clouds imply higher climate sensitivity, Science, 352, 224-227, 2016.

Tanaka, K., Raddatz, T., O’Neill, B. C., and Reick, C. H.: Insufficient forcing uncertainty underestimates the risk of high climate sensitivity, Geophys. Res. Lett., 36, L16709, https://doi.org/10.1029/2009gl039642, 2009.

Toll, V., Christensen, M., Gassó, S., and Bellouin, N.: Volcano and Ship Tracks Indicate Excessive Aerosol-Induced Cloud Water Increases in a Climate Model, Geophys. Res. Lett., 44, 12492 12500, https://doi.org/10.1002/2017GL075280, 2017.

Tomassini, L., Reichert, P., Knutti, R., Stocker, T. F., and Borsuk, M. E.: Robust Bayesian uncertainty analysis of climate system properties using Markov chain Monte Carlo methods, J. Climate, 20, 1239-1254, https://doi.org/10.1175/jcli4064.1, 2007.

Urban, N. M., Holden, P. B., Edwards, N. R., Sriver, R. L., and Keller, K.: Historical and future learning about climate sensitivity, Geophys. Res. Lett., 41, 2543-2552, https://doi.org/10.1002/2014gl059484, 2014.

Watanabe, M., Kamae, Y., Yoshimori, M., Oka, A., Sato, M., Ishii, M., Mochizuki, T., and Kimoto, M.: Strengthening of ocean heat uptake efficiency associated with the recent climate hiatus, Geophys. Res. Lett., 40, 3175-3179, https://doi.org/10.1002/grl.50541, 2013. 